\title{
Treatment of vinasse liquid from sugarcane industry using electro- coagulation/flocculation followed by ultra filtration
}

\author{
Thirugnanasambandham Karchiyappan ${ }^{1 *}$, Roberta D. Delcolle ${ }^{2}$, Gustavo L.Goncalves ${ }^{2}$, \\ Daniel T. Vareschini ${ }^{2}$ and Marcelino L. Gimenes ${ }^{2}$
}

\author{
${ }^{1}$ Sun Yat-Sen University, Guangdong Provincial Key Laboratory of Environmental Pollution Control and Remediation \\ Technology, School of Environmental Science and Engineering, Guangzhou, 510275, China. \\ ${ }^{2}$ State University of Maringá, Department of Chemical Engineering, Av. Colombo 5790, 87020-900, Maringá-PR, Brazil. \\ "Corresponding author: e-mail: thirusambath5@gmail.com
}

\begin{abstract}
In this present work, vinasse, a by-product of sugarcane industry, was examined using combined treatment methods to purify it. Electrocoagulation/flocculation, ultrafiltration were applied as pre-treatment and post-treatment, respectively. The effectiveness of combined process was evaluated based on colour, turbidity and chemical oxygen demand (COD) removal. The efficiency of electrochemical reactor was investigated according to process variables such as retention time, electrode distance and electrolyte dose. From the results, the price to treat unit vinasse is found to be $2.5 \mathrm{US} \$ / \mathrm{m}^{3}$ under optimum conditions. FT-IR analysis of sludge obtained shows the results of electrocoagulation process. Ultrafiltration as post treatment experiments showed the enhanced removal efficiency of colour $(91 \%)$, turbidity $(88 \%)$ and COD (85\%). The results showed that electrocoagulation followed by ultrafiltration is a suitable combined technique to reduce the colour, turbidity and COD from vinasse liquid.
\end{abstract}

Keywords: Vinasse, Sugar industry, Electro coagulation, FT-IR analysis. Ultra-filtration, Zero Discharge.

\section{INTRODUCTION}

Ethanol is an alcohol with wide applications as a solvent, scent, flavoring and medicine and has long been used as fuel too ${ }^{1}$. In this sector, Brazil occupies a privileged position, leading the production of ethanol from sugarcane. At the end of the 2013/2014, Brazilian sugarcane harvesting season, approximately 27 billion liters of ethanol was produced ${ }^{2}$. However, in spite of the contribution of ethanol production to the Brazilian economy, the development of this sector has not been followed by environmental control measures, especially with respect to the most abundant effluent called vinasse or stillage, originating from the distillation of ethanol. The industrial production of ethanol by fermentation results in the discharge of large quantities of high strength liquid wastes generally called vinasse ${ }^{3}$. The production of vinasses in a sugarcane industry is in the range of 9-14 L per liter of ethanol obtained. Although, the production (Fig. 1) and the characteristics of the vinasse are highly variable depending on the raw material and the process applied to itself. These dark brown wastes are acidic ( $\mathrm{pH}: 4-5)$ and have a high organic content (COD in the range of $50-100 \mathrm{~g} / \mathrm{L}$ ). Further, its dark color hinders photosynthesis by blocking sunlight and is therefore ${ }^{4}$ deleterious to aquaticlife, when it discharged into environment without prior/partial treatment.

Generally, the vinasse is applied directly to soil, because of its organic matter and nutrient content (especially potassium, but also nitrogen and phosphorus), which makes it a good organic fertilizer for sugarcane regardless of whether it is used at ideal proportions ${ }^{5}$. Through, the soil application of vinasse represents the simplest and cheapest solution, using vinasse is that the large volume ${ }^{6}$. But, the continuous application of vinasse to the soil has the environmental impacts such as soil and groundwater contamination, salinization and seed germination inhibition. To avoid these environmental effects, changes in the national wide technical norm are required in Brazil ${ }^{7}$.

To find out the suitable treatment procedure for managing vinasse for both environmental and economic reasons, several processes have been developed to treat vinasse wastewater. For example, by biological process such as aerobic and anaerobic methods have been traditionally used for the treatment of vinasse ${ }^{8}$. Aerobic treatment processes are limited by their high energy consumption needed for aeration and high sludge production. The produced sludge in aerobic process needs further technique to degrade it. The anaerobic treatment of vinasse is often slowed or impaired due to the accumulation of suspended solids in the reactor, which lead to a reduction in the methanogenic activity and biomass wash-out ${ }^{9}$. Both, biological processes require long hydraulic retention time and large reactor volumes, high biomass concentration and controlling of sludge loss, to avoid the wash-out of the sludge. Therefore, biological

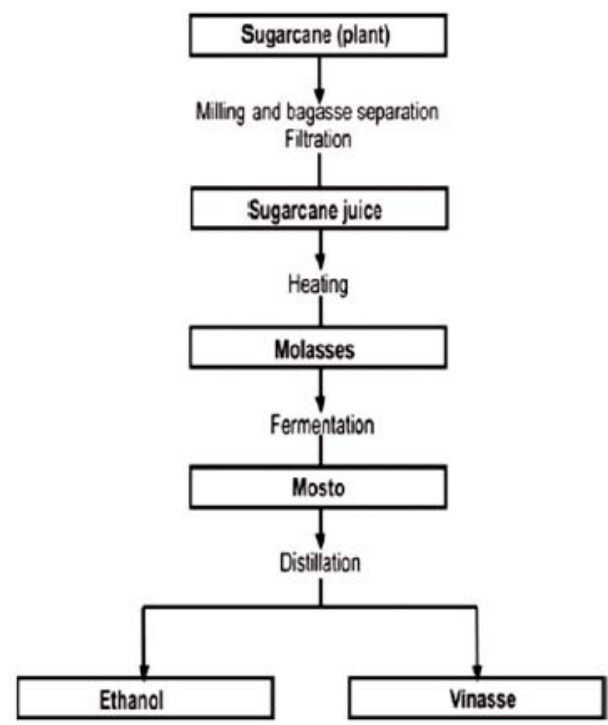

Figure 1. Production of vinasse liquid in sugarcane industry 
process to treat vinasse is still questionable, due to its lack of ability ${ }^{\mathbf{1 0}}$. Consequently, sugarcane industries have been forced to seek effective treatment technologies that are not only beneficial to the environment but also cost effective in order to fulfill the strict quality standards regarding environmental protection that are currently being developed to treat vinasse ${ }^{\mathbf{1 1}}$.

Last few decades, various physicochemical methods such as adsorption, coagulation-flocculation, and oxidation processes like Fenton's oxidation, ozonation, electrochemical oxida-tion using various electrodes and electrolytes, nanofiltration, reverse osmosis, ultrasound have also been practiced for the treatment of various industrial wastewaters ${ }^{\mathbf{1 2}}$. But, these technologies failed to achieve the maximum COD and colour removals. Still now, single technique for the effective treatment of industrial wastewater is not yet give the optimal solution ${ }^{\mathbf{1 3}}$. By applying, different combinations treatment methods, it is possible to achieve the maximum efficiency.

Electrocoagulation is the best pretreatment process of destabilizing suspended, emulsified, or dissolved contaminants in an aqueous medium by introducing an electric current into the medium ${ }^{14}$. Ultrafiltration is the effective post treatment process due to its selective contaminants removal ${ }^{15}$. Whereas, usage of ultrafiltration as pretreatment is maximum avoided due to its fouling problem. Therefore, the aim of this research was to perform the combined process using electrocoagulation (pre-treatment) followed by ultrafiltration (post-treatment) to treat vinasse liquid from sugarcane industry. Efficiency of combined process was investigated based on colour, turbidity and COD removal. FT-IR was used to find out the results of electrocoagulation process to treat vinasse. Finally, the cost of process to treat unit vinasse was also investigated in order to examine its economical viability.

\section{MATERIALS AND METHODS}

\section{Materials}

The wastewater used in this study consisted of vinasse derived from the ethanol manufacturing industry (Maringa, Parana, Brazil) and were stored at $4^{\circ} \mathrm{C}$ prior to the experiments. The characteristics of vinasse was determined using american public health association (APHA) standard methods and were shown in Table 1. Sodium chloride $(\mathrm{NaCl})$ was used as an electrolyte in the form of analytical grade.

Table 1. Characteristics of vinasse wastewater

\begin{tabular}{|l|c|}
\hline \multicolumn{2}{|c|}{ Vinasse Wastewater } \\
\hline Characteristics & Value \\
\hline $\mathrm{pH}$ & 4.65 \\
\hline Colour [pt-co unit] & 54600 \\
\hline Turbidity [FAU] & 10400 \\
\hline Chemical Oxygen Demand [mg/L] & 65000 \\
\hline
\end{tabular}

\section{Electrocoagulation experimental setup}

A laboratory batch monopolar electrocoagulation reactor (ECR) was designed and constructed as shown in Fig. 2. In the ECR, two aluminum (purity of $\mathrm{Al} 95-97 \%$ ) plate namely anode and cathode (dimension $400 \times 400$ $\mathrm{mm}$ ) were used as electrodes. These were dipped into an vinasse $(0.2 \mathrm{~L})$ in a $0.3 \mathrm{~L}$ beaker. In the ECR reactor, stirring $(50 \mathrm{rpm})$ was achieved using a magnetic bar placed between the bottom of the electrodes and the bottom of the beaker. A gelatinous deposition layer on the anode plate was cleaned for each run by hydrochloric acid $(\mathrm{HCl})$ solution. Direct current from a DC power supply (0-30 V, 0-2.5 A, ISO-TECH, IPS-1820D) was passed through the vinasse via anode and cathode. The ECR reactor operated in a galvanostatic mode which means that the current was held constant while the cell potential varied to maintain the required current. Electrocoagulation experiments were performed (in triplicate) by varing retention time, electrode distance and electrolyte dose. The samples were taken from the upper surface for color, turbidity and COD measurement.

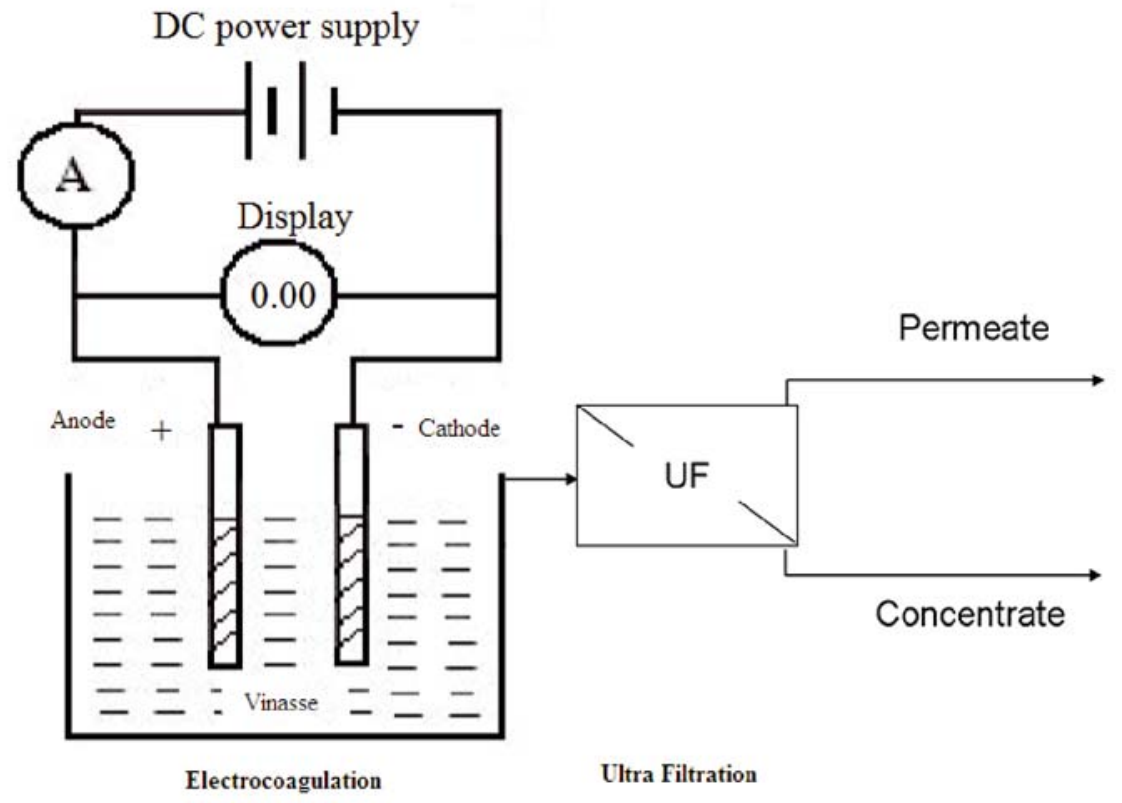

Figure 2. Schematic diagram of combined process experimental setup 


\section{Ultrafiltration experimental setup}

In ultrafiltration experiments, the tubular ceramic membranes namely $\mathrm{Al}_{2} \mathrm{O}_{3} / \mathrm{ZrO}_{2}$ made by isostatic pressing ${ }^{16}$ with a length of $175.7 \mathrm{~mm}$, diameter of $6.8 \mathrm{~mm}$ and a filtration area $0.0034 \mathrm{~m}^{2}$ are used. The experimental equipment is a micro pilot plant and ultrafiltration (UF) NETZSCH027.06-1C1/07-0005/AI model. The feeding system of the experimental module comprises a reservoir 5-liter, stainless steel, double jacketed and a pump positive displacement with frequency converter, which allows operation at different flow, that is, it enables to vary the tangential speed of filtration. The instrumentation is made up of two pressure gauges and a flow meter for flow indication of pump feeding. Safety features present in the unit are a pressure switch, which limits the pump working pressure, and a device working against dry pump. At the membranes are installed in a stainless steel module, fixed to the pipe by means of flanges. In each experiment, approximately three liter of pretreated vinasse were placed in the feed tank and it was pumped to the pressure pipe and adjusted to commence a permeate flow. All experiments were performed with a flow rate of $700 \mathrm{~L} / \mathrm{h}$, corresponding to a tangential speed approximately $8 \mathrm{~m} / \mathrm{s}$. The permeate was collected and concentrated totally recirculated to the tank feeding. The permeate samples were taken for colour, turbidity and COD measurement in the UF.

\section{Calculations}

American public health association (APHA) standard methods were used to determine the wastewater characteristics such as initial $\mathrm{pH}$, colour, turbidity and COD. The removal efficiency of colour, turbidity and COD were calculated using the following equation

$\mathrm{R}=\frac{\mathrm{C}_{0}-\mathrm{C}_{\mathrm{t}}}{\mathrm{C}_{0}} \times 100$

where $\mathrm{C}_{0}$ - initial concentration, $\mathrm{C}_{\mathrm{t}}$ - concentration after ECR treatment at time t. Electrical energy consumption (E) in ECR was calculated using equation ${ }^{17}$

$\mathrm{E}=\frac{U I t_{E C R}}{V}$

where $\mathrm{E}$ is $\mathrm{KWh} / \mathrm{m}^{3}$, $\mathrm{U}$ is the applied potential (V), I is the operating current in ampere $(\mathrm{A}), \mathrm{t}_{\mathrm{ECR}}$ is the ECR treatment time $(\mathrm{h})$ and $\mathrm{V}$ is the volume of the vinasse (L). The amount of $\mathrm{Al}$ (III) released into the treated vinasse during ECR treatment was estimated manually and it confirmed by applying Faraday's law as follows ${ }^{18}$

$\nabla \mathrm{m}_{\mathrm{t}}=\frac{\mathrm{IMt}_{\mathrm{ECR}}}{\mathrm{nF}}$

where $m_{t}$ the dissolved aluminum $(\mathrm{g}), \mathrm{n}$ is the number of electrons in the redox reaction, F is Faraday's constant and $\mathrm{M}$ is the molecular weight of $\mathrm{Al}$.

\section{Statistical experimental design}

Normally, in wastewater treatment, optimization of process variables is carried out by varying a single factor while keeping all other factors fixed at a constant level. It is not only time-consuming, but also usually incapable of reaching the true optimum, due to ignoring the interactions among variables. Response surface methodology (RSM) coupled with Box-Behnken design (BBD) is a statistical technique for designing experiments, building models, evaluating the effects of several factors and searching optimum conditions for desirable responses. In this work, BBD employed for electrocoagulation process with three important operating parameters such as retention time $(F)$, electrode diatnace $(\mathrm{G})$ and electrolyte dose $(\mathrm{H})$ were considered as the independent variables, while responses are colour removal $\left(\mathrm{Y}_{1}\right)$, turbidity removal $\left(\mathrm{Y}_{2}\right)$ and COD removal $\left(\mathrm{Y}_{3}\right)$. The low, middle and high levels of each variable were designated as $-1,0$, and +1 , respectively. The coded and actual values of the three independent variables together with their ranges are shown in Table 2. Based on BBD design empirical second-order polynomial equation was fitted to correlate the relationship between independent variables and responses. The general mathematical form of second-order polynomial equation is given as follows ${ }^{19}$

$Y=\beta_{0}+\sum_{j=1}^{k} \beta_{j} X_{j}+\sum_{j=1}^{k} \beta_{j j} X_{j}^{2}+\sum_{i} \sum_{<j=2}^{k} \beta_{i j} X_{i} X_{j}+e_{i}$

where, $\mathrm{Y}$ is the response; $\mathrm{X}_{\mathrm{i}}$ and $\mathrm{X}_{\mathrm{j}}$ are variables ( $\mathrm{i}$ and $\mathrm{j}$ range from 1 to $\mathrm{k}$ ); $\beta_{0}$ is the model intercept coefficient; $\beta_{\mathrm{j}}, \beta_{\mathrm{jj}}$ and $\beta_{\mathrm{ij}}$ are interaction coefficients of linear, quadratic and the second-order terms, respectively; $\mathrm{k}$ is the number of independent parameters $(\mathrm{k}=3$ in this study); and $e_{i}$ is the error. Further, adequacy of the mathematical model is examined using the diagnostic plots and analysis of variance (ANOVA) to find out its capacity to describe the process. The quality of the fit polynomial models were expressed by the coefficient of determination $\mathrm{R}^{2}$. Finally, the optimal conditions were obtained by analyzing the counter plots and Derringer's desired function methodology ${ }^{20}$. All the statistical experiments and model equation development were performed using Design Expert software.

Table 2. Ranges of independent variables and their levels

\begin{tabular}{|l|c|c|c|c|}
\hline \multirow{2}{*}{ Variable [unit] } & Factors & \multicolumn{3}{|c|}{ Level } \\
\cline { 2 - 5 } & $\mathrm{X}$ & -1 & 0 & 1 \\
\hline Retetion time [min] & $\mathrm{A}$ & 15 & 45 & 75 \\
\hline Electrode distance [cm] & $\mathrm{B}$ & 0.5 & 1.5 & 2.5 \\
\hline Electrolyte dose [g/L] & $\mathrm{C}$ & 0.25 & 0.75 & 1.25 \\
\hline
\end{tabular}

\section{RESULTS AND DISCUSSIONS}

\section{Mathematical model development}

Understanding the interactive effects of ECR operating parameters such as retention time $(F)$, electrode distance $(\mathrm{G})$ and electrolyte dose $(\mathrm{H})$ to treat vinasse, RSM coupled with BBD is used. Based on preliminary studies, BBD experiments consist of 17 runs is carried out (Table 3 ). To decide about the adequacy of the ${ }^{21}$ models to represent the present electrocoagulation process to treat vinasse, sequential model sum of squares was used. Cubic model was not suggested, due to insufficient F-value and the $\mathrm{p}$ value. Sequential model sum of squares indicated that the quadratic model provided the best fit to $\mathrm{BBD}$ experimental data with the higher F-value and the lowest $p$ value. Therefore, the quadratic model is chosen and the responses with the determined coefficients are presented as follows, 
Table 3. Box-Behnken experimental design and observed responses

\begin{tabular}{|l|c|c|c|c|c|c|}
\hline Run & $\mathrm{F}$ & $\mathrm{G}$ & $\mathrm{H}$ & Colour removal [\%] & Turbidity removal [\%] & COD removal [\%] \\
\hline 1 & 75 & 1.5 & 0.25 & 3.58 & 7.54 & 2.56 \\
\hline 2 & 15 & 2.5 & 0.75 & 40.58 & 50.84 & 22.38 \\
\hline 3 & 15 & 1.5 & 0.25 & 4.15 & 7.58 & 8.54 \\
\hline 4 & 45 & 0.5 & 1.25 & 45.55 & 67.54 & 24.55 \\
\hline 5 & 75 & 1.5 & 1.25 & 50.98 & 84.54 & 29.75 \\
\hline 6 & 45 & 2.5 & 1.25 & 66.51 & 80.54 & 55.87 \\
\hline 7 & 45 & 1.5 & 0.75 & 71.92 & 80.54 & 52.88 \\
\hline 8 & 45 & 1.5 & 0.75 & 71.92 & 80.54 & 52.88 \\
\hline 9 & 45 & 1.5 & 0.75 & 71.92 & 29.58 & 8.88 \\
\hline 10 & 75 & 0.5 & 0.75 & 20.85 & 24.54 & 64.47 \\
\hline 11 & 45 & 2.5 & 0.25 & 16.54 & 50.48 & 3.42 \\
\hline 12 & 75 & 2.5 & 0.75 & 55.14 & 40.54 & 15.14 \\
\hline 13 & 15 & 1.5 & 1.25 & 33.54 & 15.84 & 13.52 \\
\hline 14 & 15 & 0.5 & 0.75 & 32.54 & 80.54 & 6.55 \\
\hline 15 & 45 & 0.5 & 0.25 & 7.84 & 80.54 & 52.88 \\
\hline 16 & 45 & 1.5 & 0.75 & 71.92 & 71.92 & 52.88 \\
\hline 17 & 45 & 1.5 & 0.75 & & & \\
\hline
\end{tabular}

$\mathrm{Y}_{2}=80.54+2 \mathrm{~F}+8.49 \mathrm{G}+26.74 \mathrm{H}+6.15 \mathrm{FG}+5.36 \mathrm{FH}$

$+1.33 \mathrm{GH}-24.34 \mathrm{~F} 2-9.84 \mathrm{G} 2-21.83 \mathrm{H} 2$

$\mathrm{Y}_{3}=52.88+2.47 \mathrm{~F}+8.38 \mathrm{G}+10.14 \mathrm{H}+4 \mathrm{FG}+5.57 \mathrm{FH}$

$+3.22 \mathrm{GH}-21.43 \mathrm{~F} 2-12.01 \mathrm{G} 2-17.88 \mathrm{H} 2$

Where, $\mathrm{Y}_{1}, \mathrm{Y}_{2}$ and $\mathrm{Y}_{3}$ are colour, turbidity and COD removal, respectively. The statistical significance of the response functions $\left(\mathrm{Y}_{1}-\mathrm{Y}_{3}\right)$ are verified by ANOVA results, which are summarized in Table 4. The sufficient fit of the models are evaluated by co-efficient of variance $(\mathrm{CV} \%)$ and adequate precision (AP) ${ }^{22}$. The lower CV\% values revealed that, the developed models are capable to predict the experimental data. The value of AP values are in reasonable agreement with experimental data. The adequacy of developed mathematical models are also evaluated by $\mathrm{R}^{2}$ by plotting actual versus predicted plots (Fig. 3). The high value of $\mathrm{R}^{2}(>0.95)$ for the models indicated a high dependence and correlation between the observed and the predicted values of response ${ }^{23}$.

Effect of process variables on electrocoagulation process Contour plots (Fig. 4) are constructed from the developed models in order to study the individual and interactive effect of the process variables on the responses and also used to locate the optimal conditions for the maximum removal efficiencies of colour, turbidity and COD.

\section{Effect of retention time}

In ECR to treat vinasse, retention time is the significant parameter which is directly involved with production of coagulants. In order to examine the effect of retention time on the maximum removal efficiency of colour, turbidity and COD, experiments are carried out in diverse retention time and results are depicted in Fig. 4 (a, c and e). From the results, it is found that the removal
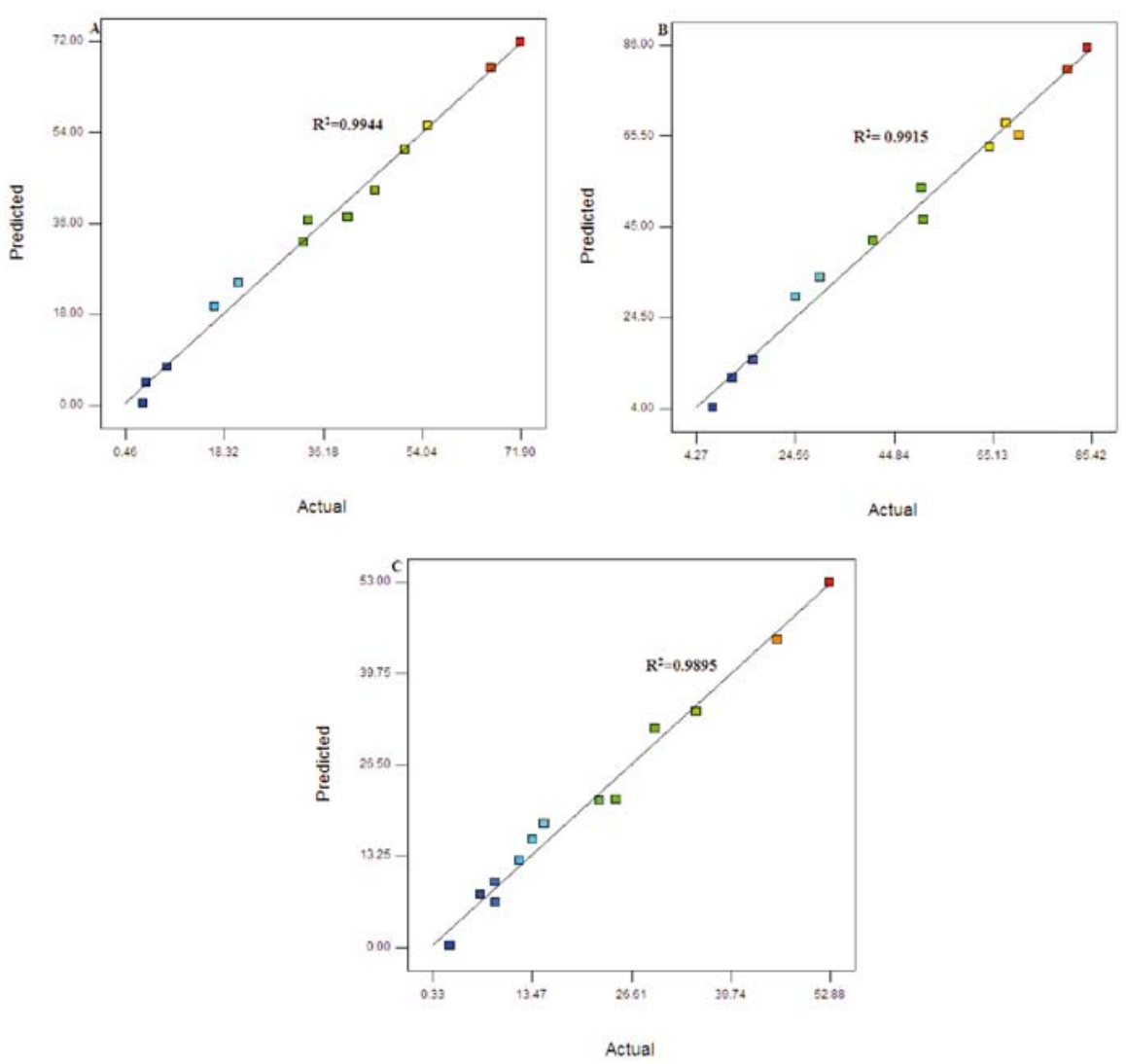

Figure 3. Actual versus predicted plot for responses a) colour removal b) turbidity removal c) COD removal 
Table 4. ANOVA table for responses

\begin{tabular}{|c|c|c|c|c|c|c|}
\hline \multirow{2}{*}{ Source } & \multicolumn{2}{|c|}{$Y_{1}$} & \multicolumn{2}{|c|}{$Y_{2}$} & \multicolumn{2}{|c|}{$Y_{3}$} \\
\hline & F value & $p$ value & F value & $p$ value & F value & $p$ value \\
\hline Model & 137.94 & $<0.0001$ & 86.92 & $<0.0001$ & 111.19 & $<0.0001$ \\
\hline A & 5.77 & 0.0474 & 2.09 & 0.1917 & 8.14 & 0.0246 \\
\hline $\mathrm{B}$ & 75.99 & $<0.0001$ & 37.55 & 0.0005 & 94.11 & $<0.0001$ \\
\hline $\mathrm{C}$ & 396.66 & $<0.0001$ & 372.79 & $<0.0001$ & 137.66 & $<0.0001$ \\
\hline$A B$ & 20.21 & 0.0028 & 9.85 & 0.0164 & 10.73 & 0.0136 \\
\hline $\mathrm{AC}$ & 9.50 & 0.0178 & 7.48 & 0.0292 & 20.81 & 0.0026 \\
\hline $\mathrm{BC}$ & 4.41 & 0.0739 & 0.46 & 0.5204 & 6.94 & 0.0337 \\
\hline$A^{2}$ & 257.78 & $<0.0001$ & 162.58 & $<0.0001$ & 323.88 & $<0.0001$ \\
\hline $\mathrm{B}^{2}$ & 68.49 & $<0.0001$ & 26.58 & 0.0013 & 101.72 & $<0.0001$ \\
\hline $\mathrm{C}^{2}$ & 334.21 & $<0.0001$ & 130.81 & $<0.0001$ & 225.46 & $<0.0001$ \\
\hline CV \% & \multicolumn{2}{|c|}{6.73} & \multicolumn{2}{|c|}{7.23} & \multicolumn{2}{|c|}{8.50} \\
\hline AP & \multicolumn{2}{|c|}{31.00} & \multicolumn{2}{|c|}{27.00} & \multicolumn{2}{|c|}{28.00} \\
\hline
\end{tabular}

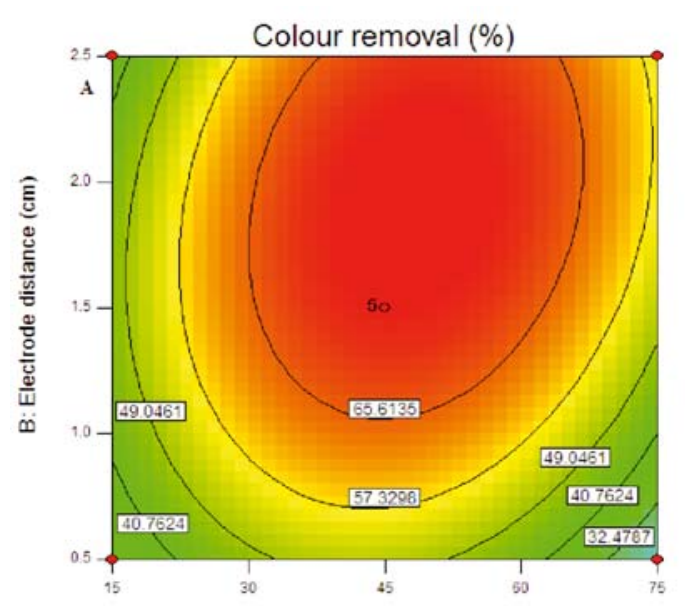

A: Retention time (min)
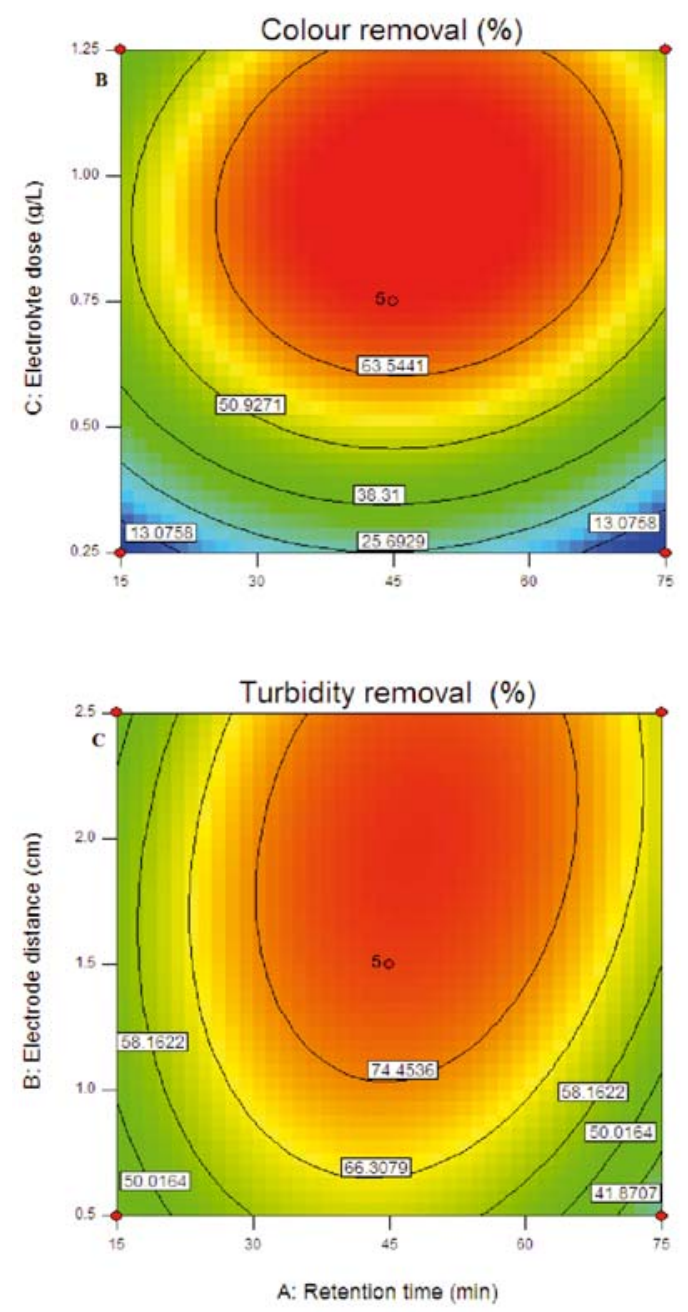

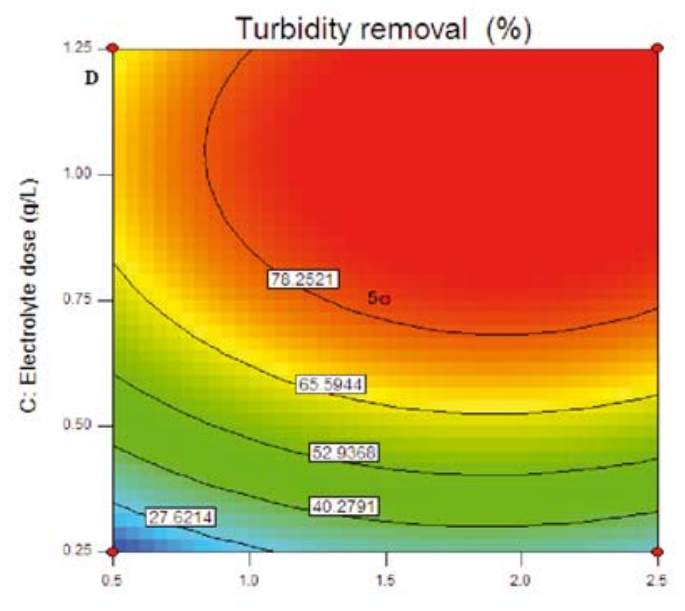

B: Electrode distance (cm)
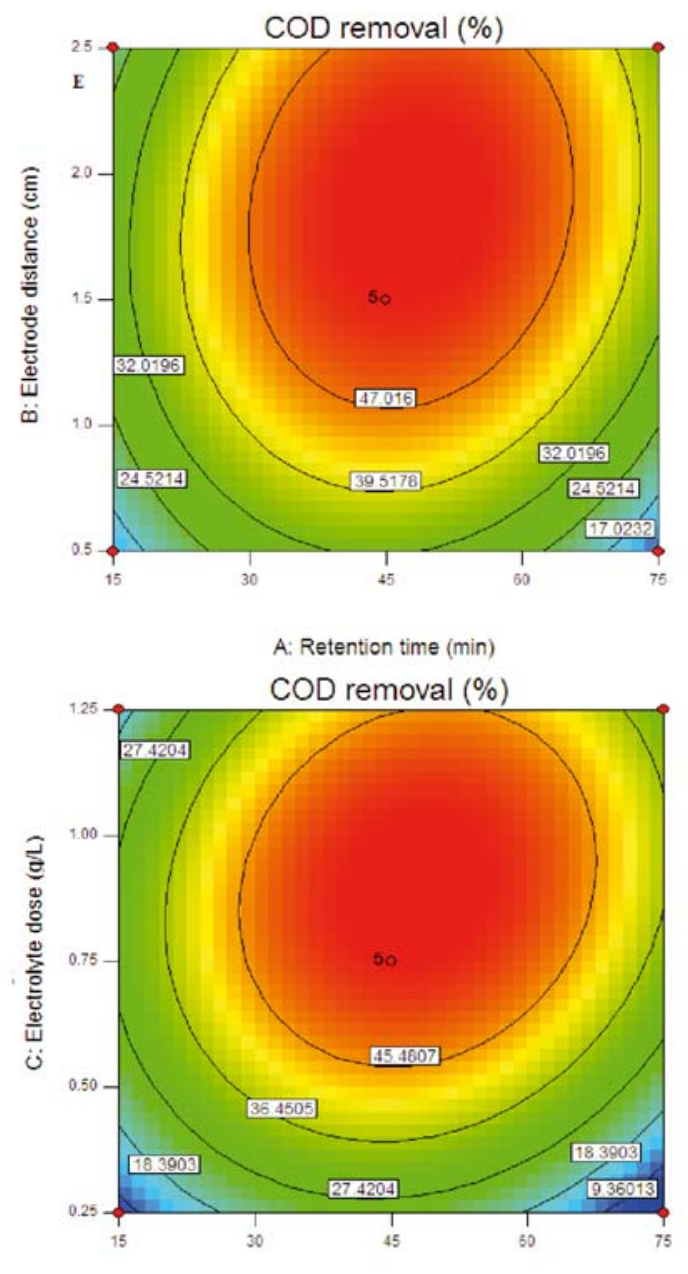

A: Retention time (min)

Figure 4. Effect of process variables (A, B, C and D) on EC treatment efficiency 
efficiency of colour, turbidity and COD are increased with increasing retention upto $50 \mathrm{~min}$. This can be due to the formation of higher amount of monomeric species in the ECR with respect to retention time as following the electrochemical reactions ${ }^{24}$

At the anode: $\mathrm{M}_{(\mathrm{s})} \rightarrow \mathrm{M}^{3+}{ }_{(\mathrm{aq})}+3 \mathrm{e}^{-}$

At the cathode: $3 \mathrm{H}_{2} \mathrm{O}_{(\mathrm{l})}+3 \mathrm{e}^{-} \rightarrow 3 / 2 \mathrm{H}_{2}+3 \mathrm{OH}^{-}$

In vinasse: $\mathrm{M}^{3+}{ }_{(\text {aq) }}+3 \mathrm{H}_{2} \mathrm{O} \rightarrow \mathrm{M}(\mathrm{OH})_{3(\mathrm{~s})}+3 \mathrm{H}^{+}{ }_{(\mathrm{aq})}$

$\mathrm{M}^{3+}(\mathrm{aq})$ and $\mathrm{OH}^{-}$ions are generated by the electrochemical reactions to form various monomeric species, which change finally into $\mathrm{M}(\mathrm{OH})_{3}$ according to complex precipitation kinetics. This amorphous $\mathrm{M}(\mathrm{OH})_{3}$ flocs with large surface areas are favorable for a rapid adsorption of organic compounds and colloidal particles in vinasse. This can also explained by the fact that when high retention time was applied to the ECR, a large amount of monomeric and polymeric metal species are produced according to Faraday's law, leading to the reduction of colour, turbidity and COD in vinasse to be treated ${ }^{25}$. Whereas, ECR treatment efficiency is decresed beyond the electrolysis time of $50 \mathrm{~min}$.

\section{Effect of electrode distance}

An electrode distance is a crucial parameter to determine the removal of colour, turbidity and COD in vinasse wastewater using electrocoagulation process. In order to evaluate its effect, experiments were performed at various electrode distance $(0.5-2.5 \mathrm{~cm})$ and the results are illustrated in Fig. 4 (a, c and e). From the results, it is found that the removal efficiencies of colour, turbidity and COD are increased with increasing electrode distance upto $1.5 \mathrm{~cm}$. Thereafter, there is a drastic decrease in removal efficiencies of colour, turbidity and COD. This can explained by the fact that, electrical conductivity is directly proportional to the distance between the two electrodes. As the distance between the anode and the cathode $(g)$ increases, resistance $(R)$ offered by the cell increases by the following relation ${ }^{26}$

$\mathrm{R}=\frac{\mathrm{g}}{\mathrm{KA}}$

where $K$ is the cell specific conductance and $A$ is electrode surface area. And, therefore, the current in the cell decreases at constant voltage by the relation: current $=$ voltage/resistance. Thus production of $\mathrm{M}(\mathrm{OH})_{3}$ (metal hydroxide) is decreased, which reduced the removal efficiencies, significantly.

\section{Effect of electrolyte dose}

Electrolyte $(\mathrm{NaCl})$ dose is one of the essential parameter in electrocoagulation process to treat vinasse in ECR. In order to inspect the effect of electrolyte dose on the ECR treatment efficiency, various electrolyte doses are examined and results are shown in Fig. 4 (b, $\mathrm{d}$ and f). It can be seen from results that the percentage of removal efficiencies of colour, turbidity and COD are increased with an increase in the electrolyte dose upto 1 $\mathrm{g} / \mathrm{L}$. This phenomena can be attributed due to the fact that the addition of electrolyte to the vinasse involved the following reactions ${ }^{27}$

$2 \mathrm{Cl}^{-} \rightarrow \mathrm{Cl}_{2}+2 e^{-}$

$\mathrm{Cl}_{2}+\mathrm{H}_{2} \mathrm{O} \rightarrow \mathrm{HOCl}+\mathrm{Cl}^{-}+\mathrm{H}^{+}$

$\mathrm{HOCl} \rightarrow \mathrm{OCl}^{-}+\mathrm{H}^{+}$
As shown in reactions (12-14), the electrochemically generated $\mathrm{Cl}_{2}$ and $\mathrm{OCl}^{-}$served as a strong oxidant species that could oxidize organic compounds in the vinasse. Beyond $1 \mathrm{~g} / \mathrm{L}$ of electrolyte dose shows the negligible colour, turbidity and COD removal in electrocoagulation process. However, it is believed that $\mathrm{NaCl}$ dose resulted in the reduction of cell voltages, due to increase of conductivity, which could cause a decrease in electrical energy consumption indirectly operating cost.

\section{Optimization}

In order to find out the optimum operating conditions to treat vinasse using electrocoagulation process in ECR is carried out using Derringer's desired function methodology ${ }^{28}$. Here, process parameters are selected as within range and responses $\left(\mathrm{Y}_{1}-\mathrm{Y}_{3}\right)$ fixed as a maximize. Optimal operating conditions found to be as follows: retention time of $50 \mathrm{~min}$, electrode distance of $1.5 \mathrm{~cm}$ and electrolyte dose of $1 \mathrm{~g} / \mathrm{L}$. Under these conditions, $72 \%$ of colour, $86 \%$ of turbidity and $59 \%$ of COD removal are achieved. In order to verify the accuracy of optimal operating condition, the experiments are carried out in predicted optimum condition. The results (real experiments) showed the close agreement with predicted values and hence model is validated.

\section{Cost evaluation}

The operating cost is very important economical parameter in electrocoagulation process. The operating cost was calculated using the following equation ${ }^{29}$

Operating cost (US $\left.\$ / \mathrm{m}^{3}\right)=\mathrm{aC}_{\text {energy }}+\mathrm{bC}_{\text {electrode }}+$ $\mathrm{cC}_{\text {chemicals }}$

Where $\mathrm{C}_{\text {energy }}$ is the energy consumption $\left(\mathrm{kWh} / \mathrm{m}^{3}\right)$, $\mathrm{C}_{\text {electrode }}$ is the electrode consumption $\left(\mathrm{kg} / \mathrm{m}^{3}\right)$ and $\mathrm{C}_{\text {che- }}$ micals is the chemical consumption $\left(\mathrm{kg} / \mathrm{m}^{3}\right)$. Unit prices $\mathrm{a}, \mathrm{b}$ and $\mathrm{c}$ given for the price at Brazil is as follows: (a) electrical energy price $0.2 \mathrm{US} \$ / \mathrm{kWh}$, (b) electrode material (Al) price 1.6 US $\$ / \mathrm{kg}$, (c) electrolyte $(\mathrm{NaCl})$ price 0.008 US $\$ / \mathrm{kg}$. From the results, the price to treat unit vinasse is found to be $2.5 \mathrm{US} \$ / \mathrm{m}^{3}$ under optimum conditions to treat vinasse by ECR.

\section{FT-IR analysis of sludge}

Sludge from electrocoagulation process was investigated using Fourier transform infrared (FT-IR) analysis and the result is shown in Fig. 5. The broad band around $1090 \mathrm{~cm}^{-1}$ is attributed to hydrogen bonding from $-\mathrm{OH}$ of the precipitate. The band at $1640 \mathrm{~cm}^{-1}$ corresponds to the O-H deformation. Peaks at 1760 and $1420 \mathrm{~cm}^{-1}$ corresponding to $\mathrm{H}-\mathrm{O}-\mathrm{H}$ bond stretching at $1640 \mathrm{~cm}^{-1}$ to hydroxyl bending and $\gamma^{\prime}(\mathrm{OH})$ water bending vibration or overtones of hydroxyl bending. The peaks in the $400-1300 \mathrm{~cm}^{-1}$ region corresponded to the stretching and bending modes of $\mathrm{Al}-\mathrm{O}$. The peaks in the 500-800 $\mathrm{cm}^{-1}$ region corresponded to the stretching and bending modes of $\mathrm{Al}-\mathrm{O}$. Peaks at $612 \mathrm{~cm}^{-1}$ corresponded to vibrations of $\mathrm{Al}-\mathrm{O}^{30}$. Hence, it is belived that there is formation of hydroxide species, which is responsible for coagulation process.

\section{Combined treatment of electrocoagulation followed by ultra filtration}

In post-treatment technique, the vinasse wastewater, pretreated by the electrocoagulation process is investiga- 


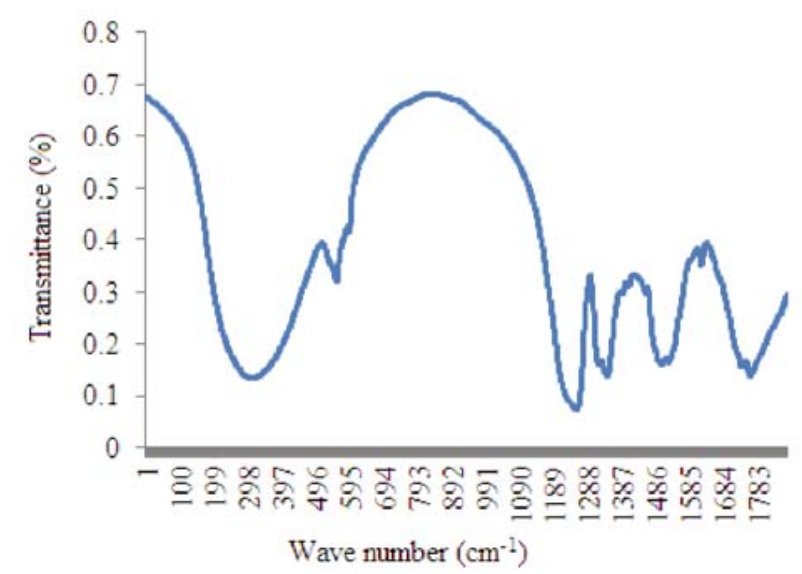

Figure 5. FT-IR analysis of sludge

ted using the ultrafiltration process. The experiments are conducted in the range as follows: temperature of $60^{\circ} \mathrm{C}$ and pressure of 3.5 bar and results are shown in Table 5 . From the results, it is found that remarkable increase in the removal of colour, turbidity and COD compared to electrocoagulation process, which is probably due to the high concentration of organic and/or suspended particles in the vinasse are effectively removed ${ }^{31}$. As shown in Table 5, electrocoagulation followed by the ultrafiltration process demonstrates more than $85 \%$ of removal in colour, turbidity and COD. The EC pretreatment strategies successfully reduce the contaminantes and it's product is suitable for discharge (Fig. 6). It is concluded that under developed conditions, EC pretreatment would improve ultrafiltration performance in water quality.

Table 5. Characteristic of vinasse after electrocoagulation (EC) and after EC followed by ultrafiltration $(\mathrm{EC}+\mathrm{UF})$

\begin{tabular}{|l|c|c|c|}
\hline Characteristics & Value & After EC [\%] & $\begin{array}{c}\text { After EC+ UF } \\
{[\%]}\end{array}$ \\
\hline $\mathrm{pH}$ & 4.78 & 5.9 & 5.8 \\
\hline Colour & 54600 & 72 & 91 \\
\hline Turbidity & 10400 & 86 & 88 \\
\hline COD & 70800 & 59 & 85 \\
\hline
\end{tabular}

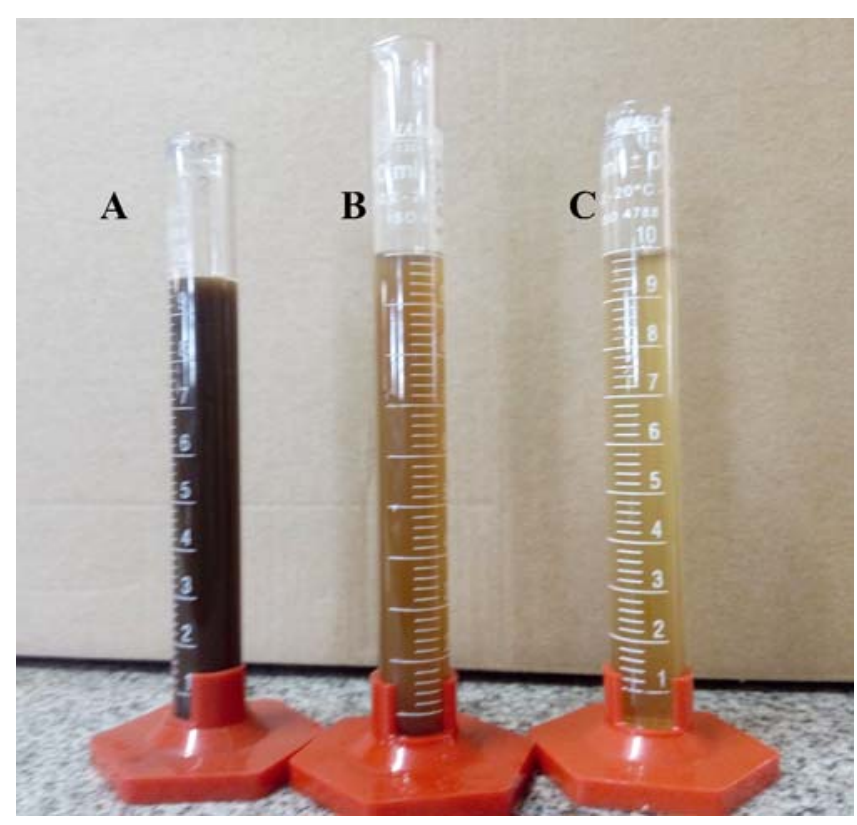

Figure 6. Raw vinasse (a) after EC (b) and after EC+UF (c)

\section{Comparision with literature report}

In order to compare the efficiency of proposed treatment technique, the achieved results are compared with existing literature report. Treatment of vinasse by using electro-dissolution and chemical flocculation study reported that only 54\% of COD are removed in optimum conditions ${ }^{32}$. In another study, vinasse treatment by coupling of electro-dissolution, hetero-coagulation and anaerobic digestion showed the $83 \%$ COD removal in optimum conditions ${ }^{33}$. From the results, it is found that current proposed method showed the $85 \%$ COD removal. Hence, it is proved that the proposed method has the more removal efficiency that exisiting ones.

\section{CONCLUSION}

Electrocoagulation process followed by ultrafiltration is addressed to treat vinasse for the maximum removal of colour, turbidity and COD. Electrocoagulation process is examined based on operating parameters such as such as retention time, electrode distance and electrolyte dose using aluminium electrodes. Three factors three levels Box-Behnken design (BBD) was used to develop the second order polynomial mathematical models. Optimum operating conditions was found to be as follows: retention time of $50 \mathrm{~min}$, electrode distance of $1.5 \mathrm{~cm}$ and electrolyte dose of $1 \mathrm{~g} / \mathrm{L}$. Under these conditions, $72 \%$ of colour, $86 \%$ of turbidity and $59 \%$ of COD removal are achieved with cost of 2.5 US $\$ / \mathrm{m}^{3}$. FT-IR analysis of sludge obtained shows the results of electrocoagulation process. Ultrafiltration as post treatment experiments showes the enhanced removal efficiency of colour, turbidity and COD.

\section{ACKNOWLEDGMENTS}

The authors are thankful to Coordination for the Improvement of Higher Education Personnel (CAPES), Brazilian Government agency for the financial support to conduct this research work.

\section{LITERATURE CITED}

1. Zayas, T.P., Geissler, G. \& Hernandez, F. (2007). Chemical oxygen demand reduction in coffee wastewater through chemical fl occulation and advanced oxidation processes. $J$. Environ. Sci. 19, 300-305. DOI: 10.1016/S1001-0742(07)60049-7.

2. Benincá, C., Vargas, F.T., Martins, M.L., Gonçalves, F.F., Vargas, R.P., Freire, F.B. \& Zanoelo, E.F. (2016). Removal of clomazone herbicide from a synthetic effl uent by electrocoagulation. Water Sci. Technol. 73, 2944-2952. DOI: 10.2166/ wst.2016.133.

3. Thirugananasambandham, K. \& Sivakumar V. (2015). Application of D-optimal design to extract the pectin from lime bagasse using microwave green irradiation. International J. Biolog. Macromol., 72, 1351-1357. DOI: 10.1016/j. ijbiomac.2014.09.054.

4. Thirugananasambandham, K., Kandasamy, S., Sivakumar V., Kiran kumar, R. \& Mohanavelu, R. (2015). Modeling of by-product recovery and performance evaluation of ElectroFenton treatment technique to treat poultry wastewater. J. Taiwan Instit. Chem. Engine. 46, 89-97. https://doi.org/10.1016/j. jtice.2014.09.004.

5. Abdel, S.G.A., Baraka, A.M., Omran, K.A. \& Mokhtar, M.M. (2012). Removal of Some Pesticides from the Simulated 
Waste Water by Electrocoagulation Method Using Iron Electrodes. Int. J. Electrochem. 7, 6654-6665.

6. Aitbara, A., Cherifi , M., Hazourli, S. \& Leclerc, J.P. (2016). Continuous treatment of industrial dairy effl uent by electrocoagulation using aluminum electrodes. Desalin. Water. Treat. 57, 3395-3404. DOI: 10.1080/19443994.2014.989411.

7. Mollah, M.Y.A., Morkovsky, P., Gomes, J.A.G., Kesmez, M., Parga, J. \& Cocke, D.L. (2004). Fundamentals, present and future perspectives of electrocoagulation. J. Hazard. Mater. 114, 199-210. DOI: 10.1016/j.jhazmat.2004.08.009.

8. Moradi, M., Eslami, A. \& Ghanbari, F. (2016). Direct Blue 71 removal by electrocoagulation sludge recycling in photo-Fenton process: response surface modeling and optimization. Desalin. Water. Treat. 57, 4659-4670. DOI: 10.1080/19443994.2014.995714.

9. Bui, H.M. (2016). Modeling the removal of Sunfi $x$ Red S3B from aqueous solution by electrocoagulation process using artifi cial neural network. J. Serb. Chem. Soc. 81, 959-974. DOI: 10.2298/JSC160108032M.

10. Heffron, J., Marhefke, M. \& Mayer, B.K. (2016). Removal of trace metal contaminants from potable water by electrocoagulation. Sci. Rep. 6, 1-9. DOI: 10.1038/srep28478.

11. Daneshvar, N., Khataee, A.R., Amani Ghadim, A.R. \& Rasoulifard, M.H. (2007). Decolorization of C.I. Acid Yellow 23 solution by electrocoagulation process: Investigation of operational parameters and evaluation of specifi c electrical energy consumption (SEEC). J. Hazard. Mater. 148, 566-572. DOI: 10.1016/j.jhazmat.2007.03.028.

12. Gengec, E., Kobya, M., Demirbas, E., Akyol, A. \& Oktor, K. (2012). Optimization of baker's yeast wastewater using response surface methodology by electrocoagulation. Desalination 286, 200-209. DOI: 10.1016/j.desal.2011.11.023.

13. Thirugananasambandham, K. \& Sivakumar V. (2017). Microwave assisted extraction process of betalain from dragon fruit and its antioxidant activities, J. Saudi Soc. Agric. Sci. 16, 41-48. http://dx.doi.org/10.1016/j.jssas.2015.02.001. ISSN: 1658-077X.

14. Thirugananasambandham, K. \& Sivakumar, V. (2016). Enhancement of shelf life of coriandrum sativum leaves using vacuum drying process: Modeling and Optimization. JJ. Saudi Soc. Agric. Sci., 15, 195-201. https://doi.org/10.1016/j. jssas.2014.12.001.

15. Thirugananasambandham, K., Sivakumar, V. \& Prakash Maran, J. (2015). Evaluation of an electrocoagulation process for the treatment of bagasse -based pulp and paper industry wastewater. Environmental Progress and Sustainable Energy Volume 34, 411-419, 2015. DOI 10.1002/ep.12001.

16. Caixeta, L.B., Pedrosa, E.M.R., Guimarães, L.M.P., Barros, P.A. \& Rolim, M.M. Changes in soil and nematode community after sugarcane harvest and vinasse application. Nematropica 41 (2011) 271-280. https://doi.org/10.1016/j. energy.2018.02.102.

17. Thirugananasambandham, K. \& Sivakumar, V. (2015). Eco-friendly approach of copper (II) ion adsorption on to cotton seed cake and its characterization: Simulation and Validation. J. Taiwan Instit. Chem. Engin., 50, 198-204. https:// doi.org/10.1016/j.jtice.2014.12.002.

18. Prakash Maran, J., Sivakumar, V., Thirugananasambandham, K. \& Sridhar, R. (2013). Multi-response analysis and optimization of extraction of biologically active compounds from pulp of Indian jamun fruit. Food Sci. Biotech. 23, 9-14. https://link.springer.com/article/10.1007/s10068-014-0002-y.

19. Barros, V.G., Duda, R.M. \& Oliveira, R.A., Biomethane production from vinasse in upflow anaerobic sludge blanket reactors inoculated with granular sludge, Brazilian J. Microb. 47 (2016) 628-639. https://doi.org/10.1016/j.jenvman.2016.05.061

20. Thirugnanasambandham, K., Siva Kumar, V. \& Shine, K. (2016). Studies On Treatment Of Egg Processing Industry Wastewater Using Electrocoagulation Method: Optimization Using Response Surface Methodology. Desalination and Water
Treatment. 57, 21721-21729. https://doi.org/10.1080/19443994 .2015.1129504.

21. Christofoletti, C.A., Escher, J.P., Correia, J.E., Marinho, J.F.U. \& Fontanetti, C.S. (2013). Sugarcane vinasse: environmental implications of its use. Waste Manag. 33 2752-2761. https://doi.org/10.1016/j.chemosphere.2018.02.179.

22. Thirugananasambandham, K. \& Sivakumar, V. (2015). Removal of eco-toxic matters from grey wastewater using Electro-Fenton treatment technique- modeling and optimization. Process Safety and Environmental Protection, 95, 60-68. http://dx.doi.org/10.1016/j.psep.2015.02.001.

23. Alves, P.R.L., Luz, T.N., Sousa, J.P. \& Cardoso, E.J.B.N., Ecotoxicological characterization of sugarcane vinasses when applied to tropical soils, Sci. Total Environ. 526 (2015), 222-232. https://doi.org/10.1016/j.scitotenv.2018.02.029

24. Thirugananasambandham, K., Sivakumar, V. \& Prakash Maran, J. (2014). Modeling and investigation of submerged fermentation process to produce extracellular polysaccharide using lactobacillus confusus, Carbohydrate polymers. 114, 43-47. doi: 10.1016/j.carbpol.2014.07.067.

25. Zhi, G., Xue, Y., Chanhee, B., Suiyi, Z., Ying, L., Wei, F., Mingxin, H., Menachem Elimelech \& Xia Yang, Self-cleaning anti-fouling hybrid ultrafiltration membranes via side chain grafting of poly(aryl ether sulfone) and titanium dioxide. J. Membrane Sci. 29 (2017) 1-10. https://doi.org/10.1016/j. cej.2018.02.088.

26. Thirugananasambandham, K., Sivakumar, V., Prakash Maran J. \& Kandasamy, S. (2014). Application of response surface methodology for optimization of chemical coagulation process to treat rice mill wastewater. Environ. Sci.: Indian J., 9, 237-247.

27. Thirugnanasambandham, K. \& Siva Kumar, V. (2015). Enzymatic catalysis treatment method of meat industry wastewater using lacasse: Modelling and Optimisation, Journal of Environmental Health Science and Engineering. 13, 86-92, DOI: $10.1186 / \mathrm{s} 40201-015-0239-2$.

28. Thirugnanasambandham, K. \& Siva Kumar, V. (2016). Modeling and Optimization Of Treatment Of Milk Industry Wastewater Using Chitosan-Zinc Oxide Nanocomposite, Desalination and Water Treatment. 57, 18630-18638. https://doi. org/10.1080/19443994.2015.1102089.

29. Cardona, C., Machuca-Martínez, F. \& Cabrales, N.M. (2013). Treatment of vinasse by using electro-dissolution and chemical flocculation, Ingeniería y Competitividad. 15, 191-200. https://doi.org/10.1016/j.watres.2017.11.057.

30. Paz-Pino, O.L., Barba, L.E. \& Cabrales, N.M. (2014). Vinasse treatment by coupling of electro-dissolution, hetero-coagulation and anaerobic digestion, Dyna rev.fac.nac.minas. . 8, 187-195. https://doi.org/10.1016/j.compchemeng.2018.01.003.

31. Liu, B., Qu, F., Liang, H., Gan, Z., Yu, G. \& Bruggen, B. (2017). Algae-laden water treatment using ultrafiltration: Individual and combined fouling effects of cells, debris, extracellular and intracellular organic matter, J. Membrane Sci. 528. 178-186. https://doi.org/10.1016/j.chemosphere.2017.11.051.

32. Delcolle, R. (2010). Projeto e manufatura de membranas cerâmicas via prensagem isostática para separação de emulsões óleo vegetal/água por microfiltração tangencial, $\mathrm{Ph} . \mathrm{D}$. Thesis, Mechanical Engineering Post-Graduation Program, Mechanical Engineering Department, University of São Paulo, São Paulo, Brazil. https://doi.org/10.1016/j.biotechadv.2017.07.003.

33. Moraes, B.S., Junqueira, T.L., Pavanello, L.G., Cavalett, O., Mantelatto, P.E., Bonomi, A. \& Zaiat, M. Anaerobic digestion of vinasse from sugarcane biorefineries in Brazil from energy, environmental, and economic perspectives: Profit or expense?. Appl. Energy. 113 (2014). 825-835. https://doi. org/10.1016/j.chemosphere.2017.01.070. 